\title{
Development of Electricity Pricing Criteria at Residential Community Level
}

\author{
A. M. Ihbal ${ }^{1, *}$, H. S. Rajamani ${ }^{2}$, R. A. Abd-Alhameed ${ }^{2}$, M. K. Jalboub ${ }^{1}$, A. S. Elmeshregi ${ }^{1}$, M. A. Aljaddal $^{3}$ \\ ${ }^{1}$ Faculty of Engineering, Azzawiya University, Azzawiya, Libya \\ ${ }^{2}$ School of engineering, Design and Technology University of Bradford, Bradford, BD7 1DP, UK \\ ${ }^{3}$ High Vocational Institute for instructors, Regdaleen, Libya \\ *Corresponding Author: malabdo@yahoo.co.uk
}

Copyright (C) 2014 Horizon Research Publishing All rights reserved.

\begin{abstract}
In the UK there is no real time retail market, and hence no real time retail electricity pricing. Therefore domestic electricity consumers in the UK pay electricity prices that do not vary from hour to hour, but are rather some kind of average price. Real time pricing information was identified as a barrier to understanding the effectiveness of various incentives and interventions. The key question is whether we can evaluate energy management and renewable energy intervention in the behaviour of customers in real market terms. Currently only behaviour changes with respect to total consumption can be evaluated. Interventions cannot be defined for peak load behaviour. The effectiveness of the introduction of renewable energy is also hard to assess. Therefore, it is hard to justify introducing of renewable and demand side management at local community level, apart from when following government approved schemes, subsidies, and other initiatives. In this paper, a new criteria has been developed to help developers and planners of local residential communities to understand the cost of intervention, in order to evaluate where the load is when the prices are high.
\end{abstract}

Keywords Real Time Pricing, Renewable Energy Intervention, Demand Side Management, Local Community

\section{Introduction}

The restructuring of power markets has been ongoing in various countries around the world, including the UK, over the last two decades. Since the early 1990's the UK's electricity industry has changed from a government controlled monopoly to a competitive market in order to deliver a lower cost to the consumers, giving consumers the choice to select their energy supplier. In the process a commodity market for wholesale electricity transactions was established. Here electricity is traded in large volumes, mostly between electricity producers (selling the output of their power stations) and electricity suppliers (buying what their customers need).

There are four components to the electricity industry. These components are generation, transmission, distribution and retailers. The generation sector is the production process of electricity in power stations. Transmission refers to the transportation of electricity through high voltage cables. Distribution is the transportation of electricity at lower voltages and facilities to the final customers. Retailers are the people who make the sales of electricity to the final customers. Electricity markets can also be divided into wholesale, retail and balancing markets.

The wholesale market in the UK is the market for the sale and purchase of electricity between retailers and generators of electricity. The current trading arrangements in the wholesale market allow suppliers to buy the electricity they need to meet their customer's needs from the generating company of their choice, i.e. this is a competitive market.

The retail market is the market for the sale and purchase of electricity between consumers of electricity (customers) and retailers of electricity (suppliers). Retailers and generators try to match their demand and generation, respectively, to their contract levels so that they do not have a surplus or deficit of electricity. This is one of the key objectives of the trading arrangements in encouraging all participants to have contracts covering all of their generation and/or demand.

The generators may generate more or less energy than they have sold through bilateral contracts during the process of electricity production and trading. Retailers may purchase more or less power through bilateral contracts than their customers' actual consumption, and traders may buy more or less energy than they have sold. Such circumstances are regarded as being in imbalance. This energy imbalance is also bought or sold.

The balancing mechanism market is through the National Grid Company (NGC). The National Grid Company (NGC) will accept offers and bids for electricity close to real time to maintain energy balance, and also to deal with other operational constraints of the transmission system. The balancing mechanism allows electricity companies and traders to submit offers to sell energy (by increasing 
generation or decreasing consumption) to the system. These participants can also submit bids to buy energy (by decreasing generation or increasing consumption) from the system, at a price of the company's choosing. The National Grid Company will take the lowest priced offers and accept the highest priced bids. The imbalance prices, the system buy price (SBP) and system sell price (SSP), applied to imbalances, are derived largely as the weighted average prices of these accepted balancing mechanism offers and bids.

System Buy Price (SBP) is an imbalance price at which retailers settle the deficit in electricity by buying electricity to meet the demands of their customers from the suppliers. If the retailer's actual demand is lower than it has contracted for, it pays the system sell price (SSP) for the excess.

Figure 1 shows the average UK household fuel price from 1970 to 2009. The real price of electricity has increased by over a quarter since 1970, and the rise since 2003 has been much steeper: a jump of about 63 percent in only six years [1]. The cost of electricity is higher because of the costs associated with conversion, transmission, distribution and profit margins of private companies.

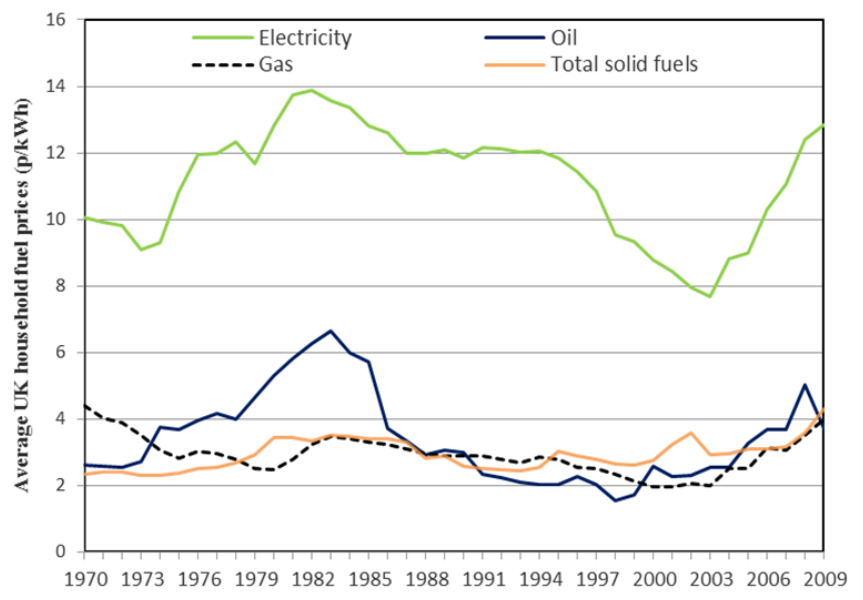

Figure 1. Average UK Household Fuel Price [1]

There have been numerous investigations dealing with electricity load profiles and electricity prices [2-9]. A tool was developed to investigate the use of tariff schemes to modify the behavior of consumers in order to achieve changes in the load profile for a local community in [2]. A technique of artificial neural network (ANN) model based on similar days method in order to forecast day-ahead electricity price in the PJM market was explored in [3]. The factors impacting the electricity price forecasting, including time factors, load factors, and historical price factors were discussed. Comparison of forecasting performance of the proposed ANN model with that of forecasts obtained from similar day's method was presented. Simulation results show that the proposed ANN model based on similar days method is capable of forecasting locational marginal price (LMP) in the PJM market efficiently and accurately.

Autoregressive moving average (ARMAX) model was adopted in [4] to reveal the linear relationship between power load and electricity price.

A study in [5] established the lack of fairness principles within the Demand response (DR) programs, as perceived by the customers to be one of the key restrictions. Fair Demand response (FDR) scheme criteria are defined and compared with existing pricing schemes. In this context, a simplified pricing model that takes into consideration fairness criteria for residential category has been also proposed. The proposed pricing model was simulated and the results were compared with that of the flat and the price based pricing schemes. In [6], a hybrid methodology that combines both ARIMA and Artificial Neural Network (ANN) models for predicting short-term electricity prices was provided. A new price forecasting method based on wavelet transform combined with ARIMA and GARCH model was proposed in [7]. In [8], a hybrid time-series and adaptive wavelet neural network (AWNN) model for the day-ahead electricity market clearing price forecast was presented. The reference [9] proposed a novel technique to forecast day-ahead electricity prices based on the wavelet transform and ARIMA models.

The previous review has shown that there are various forecasting tools which exist for planners at national level. However, at a local community level, where energy demand patterns may significantly differ from the national picture, planners would be unable to justify local and more appropriate intervention due to the lack of appropriate planning tools.

In this paper, The SBP was suggested to be used as an indicator of electricity real time price. To better capture the price fluctuations that can occur in real markets, this work took into consideration the diversification in prices the market might have.

\section{System Buy Price}

System Buy Price (SBP) is the price at which retailers settle the deficit in electricity by buying electricity from suppliers to meet the demands of their customers. It is possible to use the System Buy Price (SBP) as an indicator of electricity real price.

Figure 2 shows a sample of the half-hourly electricity System Buy Price for one week, for the time period $09^{\text {th }}$ Jan 2010 to $15^{\text {th }}$ Jan 2010 [10]. The figure shows the half hourly electricity SBP data in pounds per megawatt hour (£/MWh). As can be seen from the figure, there are two key peaks. Monday is an unusual event and has large spikes. This might be due to a sudden failure in the power grid which led to a high increase in prices in a very short period of time. 


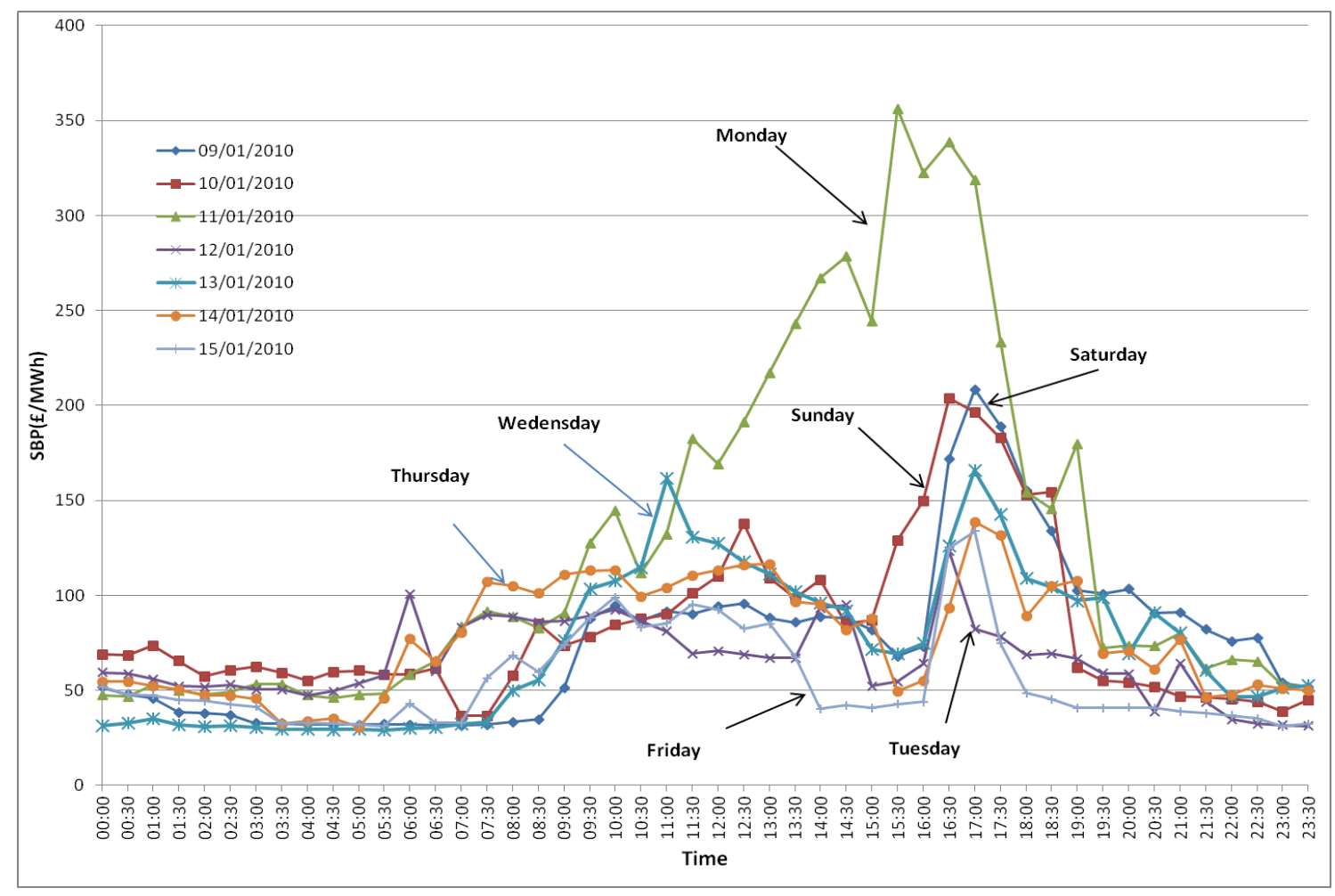

Figure 2. System Buy Price vs. Time

The half-hourly national demand data over two days is shown in Figure 3. The data was taken from the National Grid website [11].

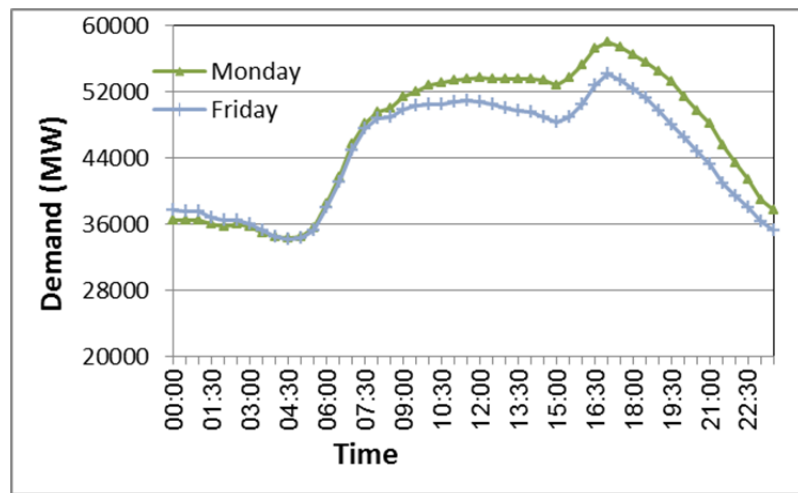

Figure 3. System Demand vs. Time

From Figure 3 it can be seen that the demand is more predictable, with less variations between days. The amount of daily demand for the whole data sets (for January, February and March) is approximately the same (ranging from $2244 \mathrm{GW}$ to about $2250 \mathrm{GW}$ ). Furthermore, there is only one key peak. We can use the demand as an indicator of price.

Considering Figure 2 and Figure 3, despite national demand not changing much, we notice peaks at different times of the day. This indicates variations in retailers predicting their own market demand. It also gives us an indication of the price retailers would be prepared to pay in real time rather than in ahead (via contracts).

If, through contractual agreement, the retailer purchases more electricity than required, then the retailer has to sell it back. The price of selling it back therefore indicates whether he is making a profit or a loss. The selling back price therefore would logically be below the contractual price or else market would naturally underbuy on contract. Therefore, the fluctuation in prices indicates the ability of the retailer to accurately forecast his demand in the future and hence the value of his contractual purchases. In other words the retailers' ability to accurately predict will help him to enter contracts in a strong position so that he does not have to buy or sell in the market. In practice, it is not possible to be perfectly accurate as that would require significant management and simulation tools. The market behaviour resolves this in an elegant way. The fact that all companies face the same issues makes the system work to the benefit of all.

The SBP prices were plotted against national demand to give an indication of the way prices rise as demand comes close to the fundamental limits of supply capacity (Figure 4).

From the figure we can see that big variations occur on Monday and slightly higher price on higher demand points. In order to model this further, a per unit system is developed in the next section. 


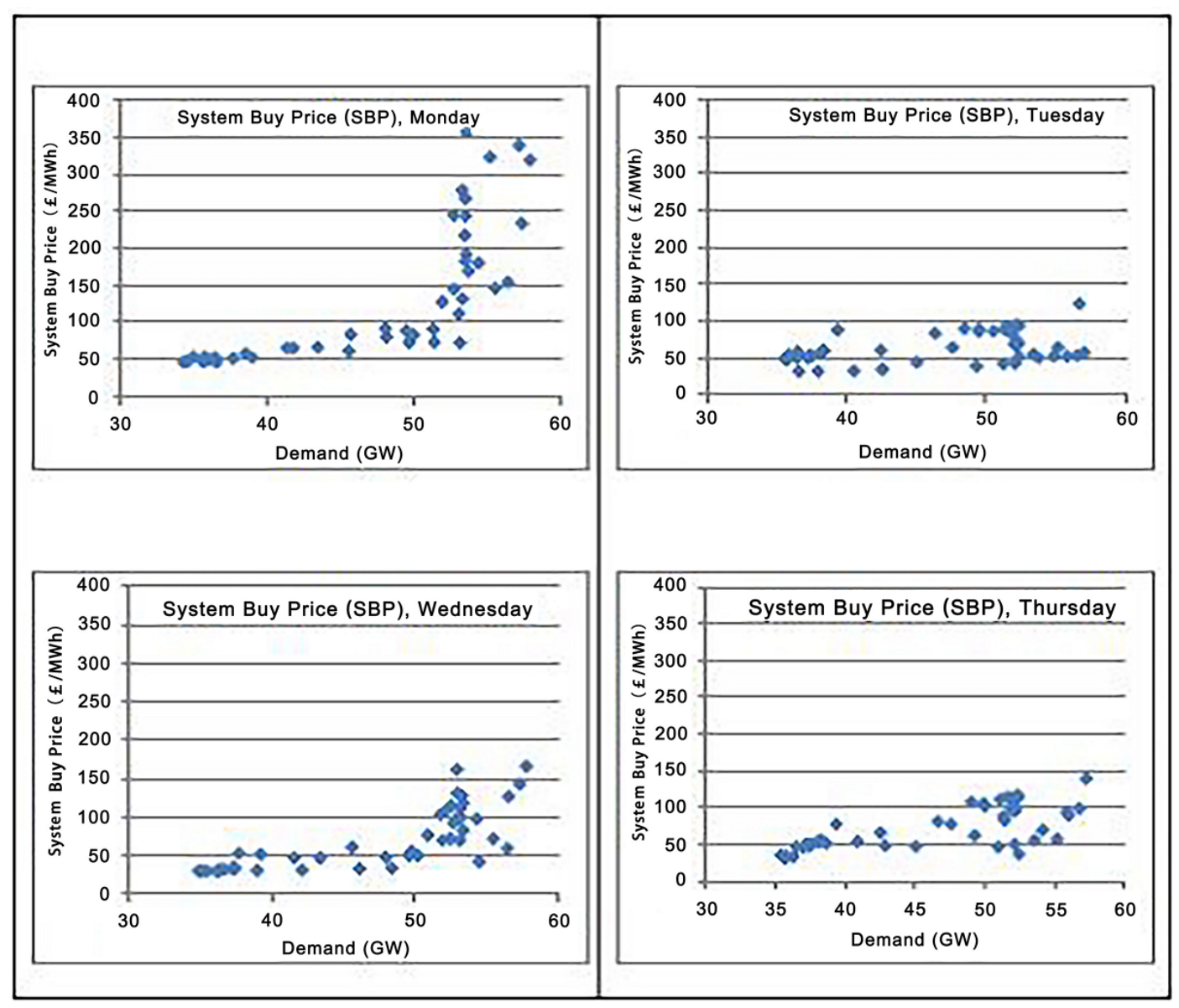

Figure 4. System Buy Price vs. demand

\section{Per Unit System}

Using per unit values allows essential characteristics of the data sets to be compared on the same diagram. This allows data on different scales to be compared, by bringing them to a common scale. Moreover, different systems can be compared. The per unit system is based on the formula shown in Equation (1).

$$
\text { per unit }=\frac{\text { Actual Quantity }}{\text { Base Quantity }}
$$

\subsection{Base Price}

The base price (BP) is the average half-hourly price. It is calculated as shown in Equation (2).

$$
\mathrm{BP}=\frac{\sum_{\mathrm{d}=1}^{\mathrm{N}} \sum_{\mathrm{i}=1}^{48} P_{d, i}}{\mathrm{~N} \times 48}
$$

Where $P_{d, i}=$ SBP rate in day d at time $\mathrm{i}, \mathrm{N}=$ Number of days.

If Equation (2) is used in abnormal situation (in sampled case) would result in a big error unless filter out the extremes or use much wider widowed data to reduce the error caused by the abnormal situation.

\subsection{Base National Demand}

The base national demand (BND) is the average half hourly demand. It is calculated as shown in Equation (3).

$$
\mathrm{BND}=\frac{\sum_{\mathrm{d}=1}^{\mathrm{N}} \sum_{\mathrm{i}=1}^{48} D_{d, i}}{\mathrm{~N} \times 48}
$$

Where $\mathrm{D}_{\mathrm{d}, \mathrm{i}}=$ national demand in day $\mathrm{d}$ at time $\mathrm{i}$.

\subsection{Base Community Demand}

The base community demand (BCD) is the average half hourly community demand for a day. It is calculated as shown in Equation (4).

$$
\mathrm{BCD}=\frac{\sum_{i=1}^{48} D_{i}}{48}
$$

Where, $D_{i}=$ Half hourly community demand at time i.

The base values were calculated for the time period $11^{\text {th }}$ Jan 2010 to $14^{\text {th }}$ Jan 2010 as shown in Table 1. 
Table 1. Summary of Base Values

\begin{tabular}{|c|c|}
\hline Base Price (£/Mwh) & 86 \\
\hline Base National Demand (Mw) & 46787 \\
\hline Base Community Demand (Kwh) & 75.3 \\
\hline
\end{tabular}

The results of the calculated per unit values for system buy price are shown in Figure 5.

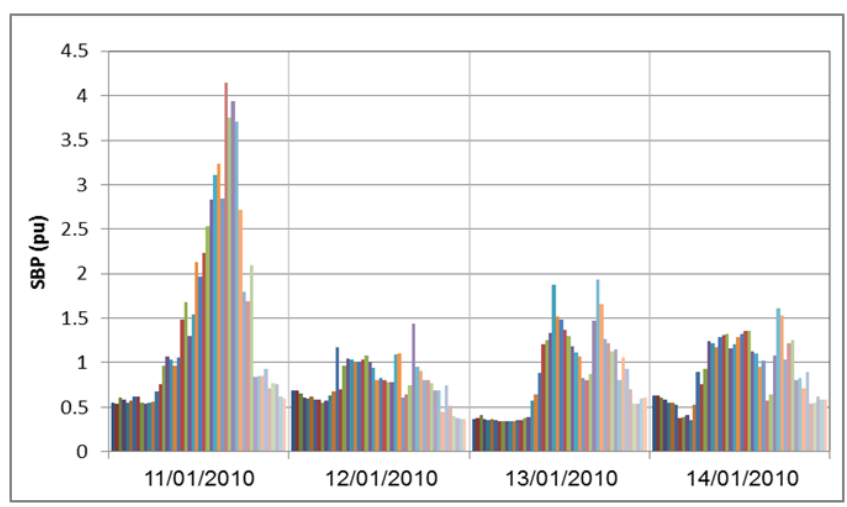

Figure 5. System Buy Price In Per Unit vs. Time

From the Figure 5, it is clear that Monday (11/01/2010) is an unusual event and the peaks on other days reach near to $1.9 \mathrm{pu}$. Note that, $1 \mathrm{pu}$ is the average.

\section{Community Electricity Cost under SBP}

The generated load profile for the local community of 400 households presented in [12,13] has been used to investigate the effect of SBP as an indicator of real time price on the electricity cost for the whole community. We are in need of a measure of dynamic load cost over the day, in order to look at the peak load shaving and a potential for a market.

The community load with SBP prices in per unit for Monday to Friday is shown in Figure 6 in a radar chart. As can be seen from the figure, the prices change basically during days and week.

The electricity cost is the sum of the products of the individual period rates and the energy consumed. Equation (5) gives the electricity cost on a time interval.

$$
C=\sum_{j=1}^{48} P_{j} \cdot D_{j}
$$

Where: $\quad \mathrm{C}=$ total electricity cost to time period $\mathrm{T}$ in $\mathrm{pu}$. $P_{j}=$ SBP rate at time $\mathrm{j}$ in $\mathrm{pu}$.

$\mathrm{D}_{\mathrm{j}}=$ Electricity consumed at time $\mathrm{j}$ in $\mathrm{pu}$.

If high SBP rates occur during periods of high power demand, consumers can see electricity cost increases above those seen with a fixed rate.

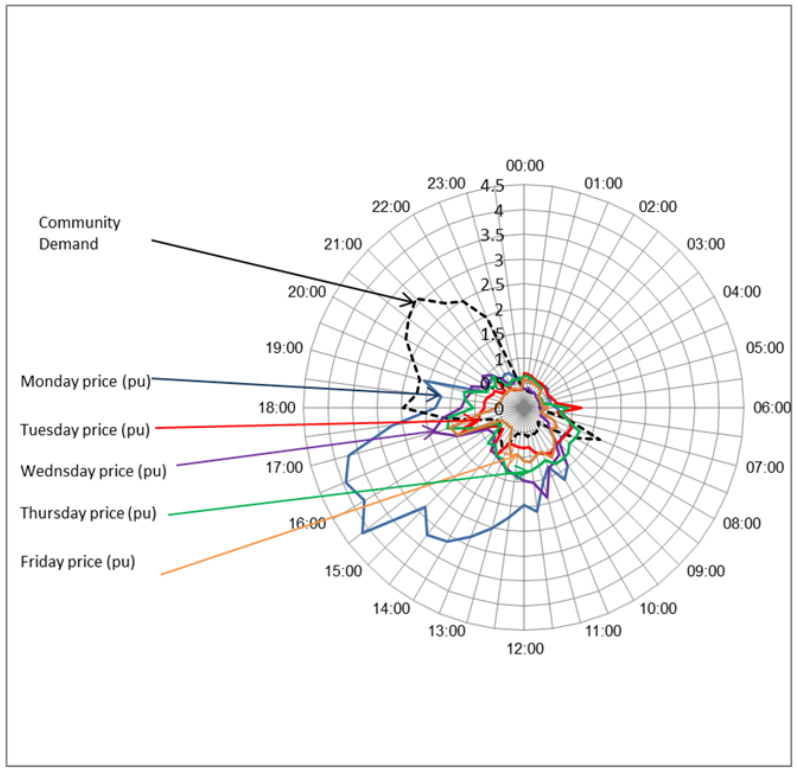

Figure 6. SBP Rate Vs. Community Demand

The electricity costs of the community have been calculated for each day. The results are shown in Figure 7.

Figure 7 shows variations in electricity cost. If we use Monday's prices we notice a very high cost around 18:00 and 19:00 of about $4.5 \mathrm{pu}$, but if we use Tuesday's prices the cost is much lower than on Monday and reaches about $2.3 \mathrm{pu}$ around 21:00 PM. Also, it can be seen that the electricity cost on Thursday is high at 19:00 and 21:00 with a value of about $2.8 \mathrm{pu}$. Moreover, the peak cost on Friday of about $1.45 \mathrm{pu}$ occurs at 17:00 and 21:00.

The load has a similar cycle but the system buy price (SBP) has a different cycle with different values for each day. As a result, the cost of electricity is different each day (Monday to Friday) reflecting the fluctuation in price. From the results we can conclude that it is very difficult to manage as indication of price keeps changing. Therefore, it is not a reliable tool for the planners.

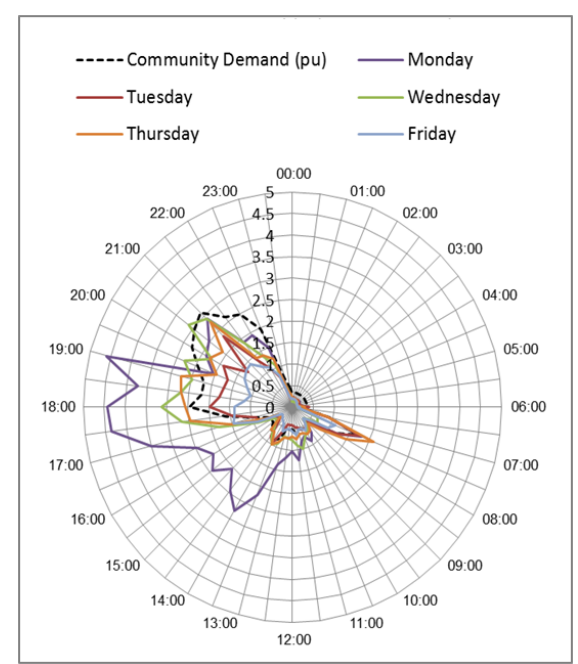

Figure 7. Community Demand and Electricity Cost Under SBP 


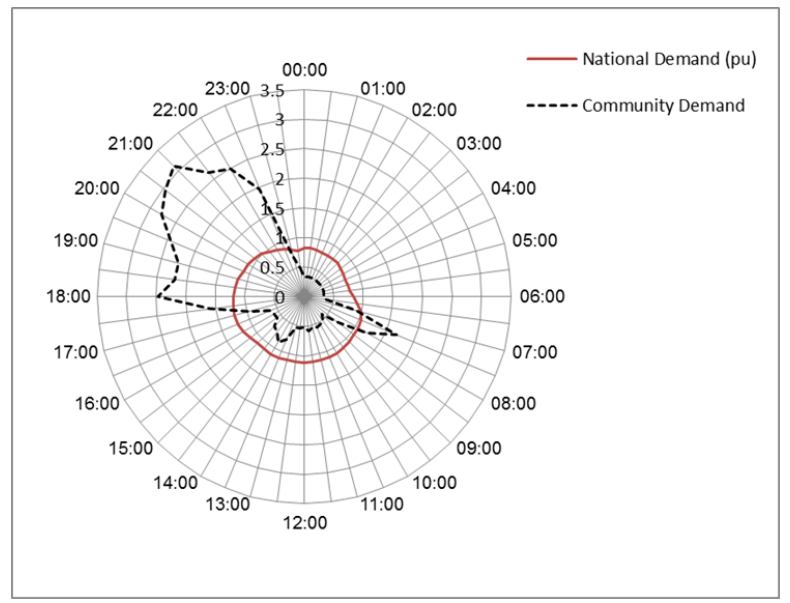

Figure 8. Community Demand vs. National Demand

Figure 8 shows the local demand plotted against national demand. From the figure, it can be seen that the national demand is more stable across the day and has a peak around 16:30 to $18: 30$. The local residential demand would naturally have peaks at different times of the day. As a result of that, investments to reduce bills under standard tariffs would therefore not have a significant impact on natural peak load (between 16:30 - 18:30). Therefore it is difficult to understand what intervention in behaviour is required using purely load behaviour.

In order to model further, three possibilities of electricity measure of system price are developed in the next section.

\section{Price Model}

When overlaid the system buy prices data for January, February and March (as shown in Figure 9 [1]), the whole data sets are not visually discernible. It can be seen that the supply capacity is in the range of about 55 to $58 \mathrm{GW}$, and that there is a considerable knee in the curve at around the $52 \mathrm{GW}, £ 100 / \mathrm{MWh}$ region. Also, there is a spread in price points for demand between 40 and $58 \mathrm{GW}$.

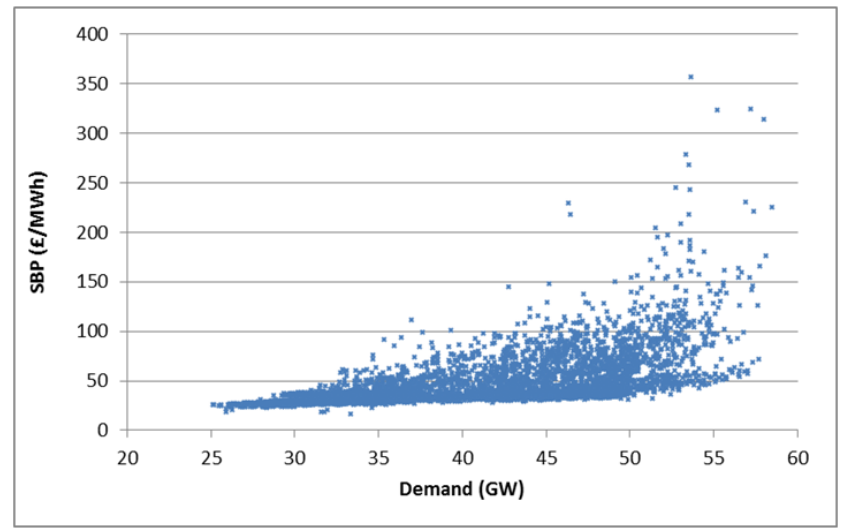

Figure 9. System Buy Price Vs. Demand (Data Combined)

Figure 9 is not useful in this form; therefore it was decided to use the quartiles as an indicator of range of prices.

In order to create three quartiles, the sample of 4318 of half-hourly national demand representing three months' data has been arranged in numerical order from smallest to largest. The national demand data is divided into 15 groups with equal intervals of 2250. Each demand group is associated with system buy price data and treated as a separate data. For each group the three quartiles of system buy price (SBP) are calculated. Each quartile is treated as a separate data. The first or bottom quartile represents the lowest price data, the second quartile or median represents the median price, and the third or upper quartile represents the highest price. Each quartile of SBP associated with demand data are treated as a dependent variable and an independent variable respectively, which means we have three dependent variables (bottom, median and upper). Each dependent variable has a single value for each demand data interval. The three fitted price equations for each scenario (quartile) were estimated using regression analysis. The computer statistical package software MINITAB has been used to get the fitted regression equation. The electricity price curves are of the form:

$$
\text { price }=a+b e^{c d}
$$

Where price is the fitted quartile electricity price in p.u and $d$ is the instantaneous national demand in p.u at that day. The resultant electricity price curves, shown as a function of demand, can be seen in Figure 10.

The resultant fitted equations for high, medium and low electricity price curves are shown in Equations 7,8 and 9 respectively. The determination coefficients for the three quartiles are $0.96,0.96$ and 0.93 respectively.

$$
\begin{gathered}
P_{\text {high }}=0.3365+1.565 \times 10^{-3} e^{5.502 d} \\
P_{\text {medium }}=0.3282+1.4523 \times 10^{-4} e^{7.175 d} \\
P_{\text {low }}=0.108 e^{1.47 d}
\end{gathered}
$$

These equations are only valid for the demand data ranging from about $0.6 \mathrm{pu}$ to $1.3 \mathrm{pu}$. The constant (a) could probably represent the minimum cost of electricity produced, $\mathrm{b}$ is a scaling factor and $\mathrm{c}$ represents the rate of change of pricing.

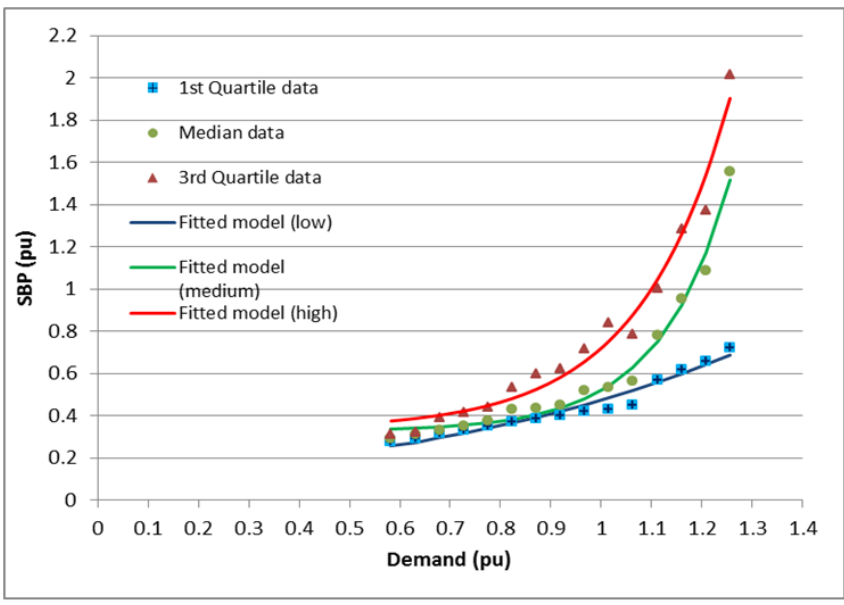

Figure 10. System Buy Price Vs. Demand (Data Combined) 
The gap between the curves at high demand shows the potential for the market. The curve also shows that at high demand the cost is a significant; up to $2 \mathrm{pu}$, whereas it can possibly be as good as $0.8 \mathrm{pu}$. The median curve also indicates that at peak level of demand the price is about 1.5 pu. Structurally, this indicates that for generators it would cost more to invest in additional generation, as this indicates infrastructure costs in future. For planners, this indicates opportunities via understanding of peak load pricing which is based on real data. Moreover, the margin of cost benefit to a local planner can be quantified in financial terms. The base value may change but as the comparison in pu the analysis will still be the same. Updated curves can always be obtained for planners.

The fitted price curves are used in the following section to forecast the half-hourly SBP which were considered as a measure of system price in order to investigate its effect on daily electricity demand.

\section{Community Electricity Cost under the New Pricing Criteria}

In this section we are looking at the community electricity cost using the three price curves. The cost of one day (Tuesday) under the three price curves is shown in Figure 11.
It can be seen that the community demand is higher at 21:00 but the cost is higher at 18:00. The cost variation at peak is ranging from $1.5 \mathrm{pu}$ to $3.5 \mathrm{pu}$.

It can be seen that the cost was about $1.5 \mathrm{pu}$ at 18:00 for the low model, $2.4 \mathrm{pu}$ at 18:00 for the medium model, and about 3.5 pu at 18:00 for the high model. From the Figure, it can be seen that the load pattern is not correlated with the price pattern, where maximum consumption periods do not coincide with periods of high price. The electricity cost at 18:00 is about $3.5 \mathrm{pu}$ with demand of about $2.5 \mathrm{pu}$. This is higher than it is at 21:00 where the cost is about $2.5 \mathrm{pu}$ with demand of 3.1pu.

The issue is that the peak is costing more so we are looking at an idea of costing. The price models are based on national demand where the local community demand has a very different pattern. Attributable to that, the cost curves do not follow the demand pattern. Therefore, the storage batteries could be used as an alternative for peak shaving and load levelling solutions; if we can shift the load a bit we will save a lot more. The planners can now think where they need to make a big effort to evaluate where the load is when the prices are high. An example, to show how we can actually use these curves in evaluating the possibility of using storage elements at community level, will be provided in the future work.

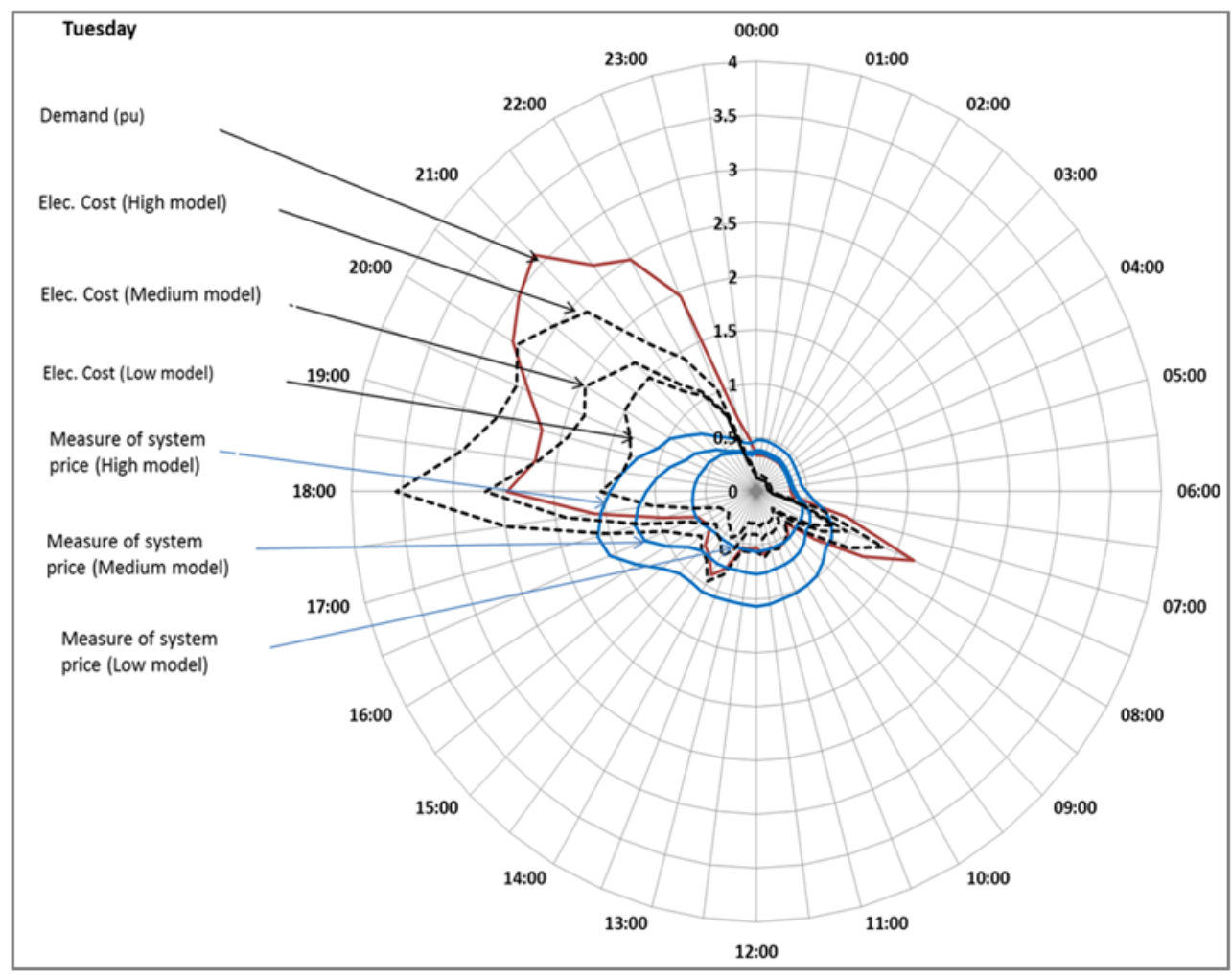

Figure 11. Electricity Cost under Three Price Model Options 


\section{Discussion}

In the UK there is no real-time retail market, and hence no real-time retail electricity pricing. Therefore, consumers do not pay based on the real-time price but rather some kind of average price, and hence have no sufficient incentives to reduce load at times of high prices or to shift their demand to other periods.

A criterion has been developed to help developers and planners of local communities to understand the cost of intervention in order to evaluate where the load is when the prices are high. The SBP was suggested to be used as an indicator of electricity real time price.

To better capture the price fluctuations that can occur in real markets, this work took into consideration the diversification in prices the market might have by developing three price curves in Figure 10 using the quartiles of SBP versus national demand. Each quartile presents a possible pricing case. There are a number of alternatives which could be used as an indicator of range of prices such as minimum, maximum or quartiles. The quartiles have been used rather than the maximum and minimum values because there is a need for an indicator that considers all the values, and not just the minimum and the maximum. The minimum value to the maximum is the range. The difficulty in assessing by range is that an extreme change in just one value drastically changes the range. So, it is not reasonable to use the maximum or minimum; they could be abnormal. The three curves are estimated based on the daily national demand data, because the national demand data is predictable and has low variations. These curves are used as an indicator of electricity real time price and demand, and are presented in pu. These curves can help planners to look at the cost of peak shaving, which is essential for developing a financial case for investment in this market.

Presenting the data in per unit value allows underlying characteristics of the data sets on different scales to be compared by bringing them to a common scale and makes the analysis easier.

The radar chart is proposed as the standard chart to compare the per unit values of demand, price and cost for the local community over the full day, at the nationally accepted half-hourly interval. The chart shows the data around the clock, which is often a good way of comparing several sets of performance indicators. The 24 hours of the day are in a continuous cycle. The day does not end at any arbitrary time. Visualizing data in hourly trends gives people something they can relate to in the context of their daily schedules and enables them to see the consequence of this behaviour. Although the line chart makes graphs easier to read it does not give a good indication of time and behaviour. Therefore it is not easy to conclude where problems are. Moreover, the base value is not as important as the peak value. The radar chart by definition will emphasise the peak and not the common dominator. This is critical when looking at peak prices and infrastructure costs. The radar chart provides a useful set of information and picture of performance to help consumers reduce their electricity costs in order to manage their consumption by taking advantage of lower priced hours and conserving electricity during hours when prices are higher.

The developed three curves would be used as a tool to evaluate the possibility of using storage batteries at community level as an example. PV cells or other embedded could also be studied in a similar way.

\section{Conclusion}

The conclusions drawn are presented below.

- Presenting the data in per unit value allows underlying characteristics of the data sets to be compared.

- The radar (spider) chart has been proposed as a standard chart to compare the per unit values of demand, price and cost for the local community for load shaving aspect.

- As no real time retail price exists in the UK, the System Buy Price (SBP) has been used as a measure of the real price based on per unit values. In order to better capture the price fluctuations that can occur in real markets, the three curves of Figure 10 have been developed using the quartiles of SBP versus demand.

- The tool developed in [4,5] can now be used alongside SBP to help planners to look at an idea of the cost of peak shaving which is essential for developing a financial case for investment in this market.

- As an example of using the tool developed in [4] and system buy pricing, the possibility of using battery storage at residential community level could be evaluated.

- The introduction of such an independent retail market at local level to enable electricity transactions between communities with embedded generation capabilities requires further research.

\section{REFERENCES}

[1] J. Palmer and I. Cooper, "Great Britain's housing energy fact file," Department of Energy and Climate change, 2011.

[2] A. M. Ihbal, H. S. Rajamani, R. A. Abd-Alhameed, and M. K. Jalboub, " Investigation of Tariff Initiatives for Peak Load Balancing at the Domestic Level," in Transactions on Systems, Signals \& Devices, Vol. 7, No. 2, pp.19-17.

[3] Paras Mandal, Naomitsu Urasaki, Anurag K. Srivastava, "A Novel Approach to Forecast Electricity Price for PJM Using Neural Network and Similar Days Method," IEEE Trans on Power Systems, vol. 22(4), pp.1058-1065, 2007.

[4] Jianhua Zhang; Jian Han; Rui Wang; Guolian Hou 
"Day-ahead electricity price forecasting based on rolling time series and least square-support vector machine model", Control and Decision Conference (CCDC), 2011 Chinese, On page(s): $1065-1070$

[5] Vuppala, S.K.; Padmanabh, K.; Bose, S.K.; Paul, S., "Incorporating fairness within Demand response programs in smart grid," Innovative Smart Grid Technologies (ISGT), 2011 IEEE PES, vol., no., pp.1,9, 17-19 Jan. 2011.

[6] Areekul, P.; Senjyu, T.; Toyama, H.; Yona, A., "Notice of Violation of IEEE Publication Principles, A Hybrid ARIMA and Neural Network Model for Short-Term Price Forecasting in Deregulated Market," Power Systems, IEEE Transactions on , vol.25, no.1, pp.524,530, Feb. 2010.

[7] Tan Z, Zhang J, Wangb J, Xu J., " Day-ahead electricity price forecasting using wavelet transform combined with ARIMA and GARCH models," Applied Energy, , vol.87., pp.1,9, 3606-3610, 2010.

[8] Lei Wu; Shahidehpour, M., "A Hybrid Model for Day-Ahead Price Forecasting," Power Systems, IEEE Transactions on , vol.25, no.3, pp.1519,1530, Aug. 2010.
[9] Conejo, A.J.; Plazas, M.A.; Espinola, R.; Molina, A.B., "Day-ahead electricity price forecasting using the wavelet transform and ARIMA models," Power Systems, IEEE Transactions on, vol.20, no.2, pp.1035,1042, May 2005

[10] ELEXON, "New Electricity Trading Arrangements NETA, Balancing Mechanism," ELEXON http://www.bmreports.com/bsp/SystemPricesHistoric.htm.

[11] National Grid, "Metered half-hourly electricity demands, "National Grid website: http://www.nationalgrid.com/uk/Ele ctricity/Data/Demand+Data

[12] A. M. Ihbal, H. S. Rajamani, R. A. Abd-Alhameed, and M. K. Jalboub, "The Generation of Electric Load Profiles in the UK Domestic Buildings Through Statistical Predictions," Journal of Energy and Power Engineering, vol.6 no.2, pp.250-258, 2012.

[13] A. M. Ihbal, H. S. Rajamani, R. A. Abd-Alhameed, and M. K. Jalboub, "Statistical predictions of electric load profiles in the UK domestic buildings," in Energy, Power and Control (EPC-IQ), 2010 1st International Conference on, 2010, pp. 345-350. 